\title{
Management in the heat-supplying organizations on the basis of balance models
}

\author{
Evgeny Evseev ${ }^{1}$, Tatiana Kisel $^{2, *}$ \\ ${ }^{1}$ Moscow Institute of Physics and Technology, 141701, 9, Institutskiy per., Dolgoprudny, Moscow \\ Region, Russia \\ ${ }^{2}$ Moscow State University of Civil Engineering, 129337, 26, Yaroslavskoye Shosse, Moscow, Russia
}

\begin{abstract}
Development of the heating systems, which are the part of engineering infrastructure of the cities and which are necessary for providing comfortable conditions for the cities' activity, is governed by the municipal authorities. Nowadays some requirements, connected with the need of increase in power efficiency are imposed in relation to the heating systems. The actions, aimed on the increase in the efficiency of heating systems, are usually connected with carrying out capital repair and updating of heating systems and the heat-generating equipment. That demands considerable financial resources and that in turn means the need of involvement of an investor. However at the moment investments into the heat-supplying enterprises are not attractive for the investor because of the lack of financial transparency and the mechanism of return of investments. In the article the authors offer the application of the balance method for formation of financial balance of the heat-supplying enterprise, The method will allow to consider the attraction of resources from three different sources and all the directions of expenditure of resources, including the mechanism of rationing of profit of the heat supplier. That guarantees the existence of the transparent mechanism of investments return.
\end{abstract}

\section{Introduction}

Nowadays that is absolutely impossible to imagine the modern city and the country as whole without the use of different types of energy resources, transformed to energy, which is necessary both for providing comfortable living conditions, and for work of all branches of economy as well for implementation of all kinds of activity. Fuel and energy complex plays specific part in economy and performs the significant infrastructure function, which is connected with providing the population and branches of economy with necessary municipal electric power and heat as well as fuel. Electric energy and heat are necessary for comfortable activity, and existence of the corresponding infrastructure makes up the necessary basis for formation of settlements.

In Russia there are considerable problems in the sphere of uninterrupted providing the population with heat and electric energy, that is in the sphere of providing the population

\footnotetext{
*Corresponding author: doremi2@yandex.ru
} 
with energy power comfort and safety. The most important of the problems is the high degree of wear of fixed assets of fuel-and-energy complex (it is nearly $60 \%$ power industry and the gas industry, and $80 \%$ in oil-processing industry). We will separately note that $70 \%$ of heating systems work with excess of standard service life; $20 \%$ of coppers and turbines of power plants are more than 50 years old; the accident rate increases, and the level of losses in heating systems reaches 20-30\%). Another important problem is the considerable unrealized potential of organizational and technological energy saving which is up to 40 percent of total amount of internal energy consumption.

The task of reduction of energy consumption in the Russian economy for $40 \%$ is one of strategic problems of the country, however the solution of this task requires the improvement of the control system of the fuel-and-energy complex branches, aimed on the increase in energy efficiency and ensuring the maximum energy saving during production, transportation, distribution and consumption of different types of energy.

The situation is recognized to be especially sharp for the heating systems. In fact the heating systems have regional and even municipal binding (work in a certain territory), they are technologically connected within this territory, and their state regulation is certain and uniform for this territory and, respectively, authorized by federal or regional executive authorities or local government. Lately the indicators of wear of fixed assets of heat supply have increased up to $65-70 \%$, the efficiency of the established power plants has decreased to not more than $50 \%$, losses in heating systems have increased and also the electric power expense on transportation of the heat carrier has considerably grown.

The need for large investments for providing reliable heat supply in the conditions of the necessity of simultaneous restriction of growth of cost of services of this sphere is revealed as the cause of the specified problems of heat supply.

It should be noted that the domestic and foreign theory and practice recognize various approaches, methods and instruments of the increase in energy efficiency, first of all, due to the energy saving realized at the enterprises as by their own forces, and with involvement of the energy-service organizations and implementation of energy-service contracts. However, the majority of these methods and tools concern technical and technological subsystems of management of the industrial enterprise [1, 2, 3]. At the same time any organizational-and-economic mechanisms of energy efficiency and energy saving management are practically not mentioned. Therefore, it is necessary to consider the expansion of the existing methodological ideas of organizational-and-economic aspects of energy efficiency management at the industrial enterprises, and thus the relevance of the research has been caused.

\section{Terms and methods}

At the moment the situation with heat supply in Russia is recognized to be critical. The lack financing of the development of the heat-supplying organizations is recognized to be the main reason of a situation in the branch: the organizations' own means and also subsidies from the budgetary system are not enough for updating of fixed assets. The branch is unattractive for investors, owing to the insufficiently transparent mechanism of return of means at the expense of the income which is rigidly regulated by tariffs for heat, gained in the estimated prospect.

Respectively, there is the necessity of planning of accumulation, distribution of financial resources, taking into account balancing of requirement with opportunities of their satisfaction. It proves the relevance of application of a balance method and balance models, aimed on elimination of the problems, arising in the heat supply industry.

The balance method is one of the traditional and widespread methods of planning. It allows to carry out comparison of requirements and resources (both available and 
perspective). The essence of the balance method consists in the identification and the quantitative characteristic of the relations between the parties of any activity, which counterbalance each other. This method is applied for a wide range of tasks, including balances of fixed assets and production capacities, work and labour, financial, transport, fuel, etc. That in turn means that balances are subdivided on cost (expressed in cost indexes) and natural and grocery (expressed in physical units). Balance models can cover the systems of various level - from business unit in the enterprise or the separate enterprise to the region, branch or the economy in general combining data on a set of branches. The mathematical model of inter-industry balance was offered by W. Leontyev [5] who received the Nobel Prize in economy for that.

The universal balance method is rather widely applied in various branches of economy, and the energy is not an exception. Balance models in this or that case are used both at the level of the enterprise, and at the level of municipalities, regions and the country in general and even at world level [6, 7, 8, 9]. Various levels of formation of energy balances determine also features of their formation. At the same time energy balances can be used, as for the analysis of the ratio of energy sources and the directions of its expenditure existing, at the moment, and for the forecast taking into account development of branches and dynamics of need for these or those types of energy resources. The power balance reflects a ratio of the energy sources and the directions of its use representing two main balance components which have to be in equality in the most general sense.

Statement that balance models are widely applied in the energy industry is fairly for the energy system in general and HSO in particular. So, for example, according to power balances of the Russian Federation, according the official statistics, that largest consumer of electric energy and heat are the industrial enterprises (they consume more than $40 \%$ of heat, population consumes about $36 \%$ of total amount of heat. The rest of the heat produced is distributed among agriculture, transport and communication, construction and other branches [10]. The difference between the total amount of the heat produced and total amount of final consumption makes losses during transportation heat and consumption (Table 1).

Table 1. Energy resources balance for heat.

\begin{tabular}{|l|c|}
\hline Indicators & $\begin{array}{c}\text { Heat, million ton of } \\
\text { conditional fuel }\end{array}$ \\
\hline Resources & 177.7 \\
\hline Production - total & - \\
\hline Stock & - \\
\hline Import & 177.7 \\
\hline Total resources & - \\
\hline Distribution & 177.7 \\
\hline Export & 161.4 \\
\hline Total consumption & 16.3 \\
\hline final consumption & \\
\hline Losses during consumption and transportation & \\
\hline $\begin{array}{l}\text { From the total amount of final consumption: consumed by } \\
\text { the organizations of separate types of economic activity and by the } \\
\text { population: }\end{array}$ & 3.4 \\
\hline - agriculture, hunting and forestry & 73.1 \\
\hline - industrial production & 6.1 \\
\hline including: & \\
\hline mineral extraction & 0.7 \\
\hline including: & \\
\hline extraction of stone coal, brown coal and peat & \\
\hline
\end{tabular}




\begin{tabular}{|l|l|}
\hline oil and natural gas production; services in these areas & 4.4 \\
\hline extraction of metal ores & 0.8 \\
\hline processing productions & 56.5 \\
\hline including: & \\
\hline production of foodstuff, including drinks, and tobacco & 5.2 \\
\hline textile and sewing production & 0.4 \\
\hline production of skin, products from skin and production of \\
footwear & 0.1 \\
\hline processing of wood and production of products from wood & 0.1 \\
\hline pulp-and-paper production; publishing and printing activity & 5.5 \\
\hline production of coke and oil products & 10.4 \\
\hline chemical production & 16.4 \\
\hline production of rubber and plastic products & 0.7 \\
\hline production of other nonmetallic mineral products & 2.7 \\
\hline metallurgical production and production of finished metal & 9.6 \\
\hline products & 1.2 \\
\hline production of machines and equipment & 1.2 \\
\hline production of electric equipment, electronic and optical & 2.7 \\
\hline equipment & 10.6 \\
\hline production of vehicles and equipment & 1.0 \\
\hline production and distribution of the electric power, gas and & 3.2 \\
\hline construction & 16.3 \\
\hline transport and communication & 64.4 \\
\hline other & \\
\hline population & \\
\hline
\end{tabular}

Official statistical data prove that losses of heat during transporting and consumption make about $10 \%$, however data of the separate enterprises and results of research prove that real losses of heat in in heating systems much more exceed the data of official statistics and make about $30 \%$, whereas in the countries similar to Russia according to climatic conditions, they are limited as of $8-9 \%$. It is caused by the progressing rates of wear of heating systems, that leads to losses of heat because of damages of pipelines and high accident rate. Statistically the number of accidents per $1 \mathrm{~km}$ of heating systems fluctuates in the range from 350 to 390 . The annual gain of the heating systems, which need replacement, makes about $4 \%$ of their total length, however the speed of replacement fluctuates at the level of $2.6-2.8 \%$, because of the lack of financing. It leads to the fact that the share of the heating systems, which need replacement, steadily accrues and makes not less than $26 \%$ of their total length in country scales according to official estimates.

The changes of the law "On Heat Supply" made in Russia in 2017 prove the beginning of the reform in the branch, one of the elements of which is transition to regulation of tariffs by the method of "an alternative boiler room". It is a local source of heat supply, with which consumers (housing-and-public utilities, small consumers) can replace heatsupplying organizations as the third-party, including the system of the central heat supply. The tariff of the alternative boiler room is defined as the smallest price of heat for the consumer, at which the project of construction of a new ("alternative") boiler room, which is not dependent on the centralized sources pays off.

The new model assumes the emergence at the level of municipalities of the uniform heat-supplying organization (HSO), which is responsible for all the chain of delivery of heat to the consumer. The uniform rules and the method of determination of "ceiling price" are approved: "the ceiling price" for heat fixed for united heat-supplying organization is determined by the principle of an alternative boiler room [11]. 
Considering all the listed circumstances, it should be noted that application of balance models for planning of activity of HSO acquires special relevance at present, and balance models have to be focused not only on accounting of sources and consumers of heat, but also on accounting of sources and the direction of the use of financial resources.

\section{Results}

Formation of balance model of the HSO management is based on some objective conditions and restrictions:

1. the balance model of HSO management has to be constructed on the basis of accounting of sources of financing and the directions of expenditure of financial resources. It allows to create the model of management aimed at the financial result;

2. the need of the solution of questions of the branch financing for ensuring updating of the heating systems and the heat-generating equipment assumes the emergence or wider use of such sources of financing as means of the investor and proceeds of credit at preservation as the main source of financing of the means, arriving from subscribers as payment for services of heat supply according to the tariff. Besides, subsidies of the municipal or regional budget can serve as a source of financing. At the same time it should be noted, that as target model of the HSO work transition to financing without participation of budgetary funds, that means that work without load of the local or regional budget is provided;

3. the possibility of the use as a source of financing of loan financial resources (credits) also determines the need of account of financial resources for debt servicing (that is payment of interest by the credit) within the directions of expenditures;

4. attracting investors into the branch is possible only in the case, when the clear and transparent mechanism of return of invested funds appears. The development of balance model of HSO management and financial balance of HSO as its bases can carry out this role. For this purpose the balance model has to contain the standard size of HSO profit, settle down in the account part of balance. The standard size of profit is not included into the structure of the HSO prime cost, however it serves for covering of the expenses on taxes and fees, expanded reproduction and material stimulation of workers. Such mechanism of rationing have arrived and its inclusions in the total cost of works, it is widespread in construction branch. Attracting investors becomes possible on the basis of the mechanism of return of the invested capital, which have been put in the control system of the investment and construction project. The size of the standard profit of HSO in the structure of the account part of financial balance has to be separately justified;

5. the structure of financial balance of HSO consists of two integrated blocks representing sources of financing of HSO (SF) and the direction of expenditure of financial resources of $\mathrm{HCO}(\mathrm{DE})$ between which the balance, that is the principle $\sum \mathrm{SF}=\sum \mathrm{DE}$ has to be observed by The structure of the financial balance of HSO is presented in the table 2 .

Table 2. Financial balance of HSO.

\begin{tabular}{|l|l|}
\hline \multicolumn{1}{|c|}{ Sources of financing } & \multicolumn{1}{c|}{ Directions of expenditures } \\
\hline 1. Internal sources of financing: & 1. Providing the main production: \\
- income gained from subscribers & - energy import (purchase of energy from a third-party \\
according to the tariff; & source); \\
- income from sale of heat to the & - production of heat (including costs of purchase of fuel for \\
third-party users who are not & the subsequent transformation); \\
subscribers; & - expense of heat on own needs; \\
2. External sources of financing: & - the expenses connected with transportation and \\
- means of the investor (attracted & distribution of heat; \\
\hline
\end{tabular}




\begin{tabular}{|l|l|}
\hline financial resources); & - losses during of transportation and distribution (cost \\
financial resources); & assessment); \\
- budget subsidies. & 2. Expenses, the directed maintenance of networks and the \\
equipment and also decrease in level of their wear: \\
& - maintenance of the heat-generating equipment and \\
networks; & - monitoring of a condition of the heat-generating \\
equipment and networks; & - capital repairs of heat and the heat-generating equipment, \\
their updating; & $\begin{array}{l}\text { 3. Overhead and other expenses: } \\
\text { - expenses on the credit; } \\
\text { - the standard of profit ( provided including the mechanism } \\
\text { of return of means to the investor); } \\
\text { - overhead costs (the expenses connected with ensuring } \\
\text { activity and hiring managerial personnel). }\end{array}$ \\
\hline
\end{tabular}

According to the structure of the HSO financial balance, presented in the table 2, as the sources of financing of its activity, we can allocate external and internal sources. Internal sources of financing include, first of all, income gained from subscribers according to the established tariff (it is the main source of financing of activity of HSO) and also income from sale of heat to the third-party users who are not subscribers. The need of the solution of the question of updating of the heat-generating equipment and heating systems for the general decrease in their wear and increase in power efficiency of systems of heat supply and improvement of quality of services (including decrease in accident rate, etc.), leads HSO to the use of a wide range of external sources of financing, including proceeds of credit, means of the investor and also budget subsidies and the existence of external sources of financing, including loan and attracted financial resources. Such external source of financing as subsidies from local and regional budgets is also significant for HSO.

At the moment the whole system of granting subsidies of HSO of various form of ownership for a covering of the income half-received by HSO, because there are subscribers having privileges for payments of utilities and also coverings of losses of HSO which take place in some regions, as gained income, based for legislatively fixed tariff size does not cover the expenses of the organization, connected with heat production and transportation. Certainly, it creates considerable load of local and regional budgets. Gradual decrease in the share of subsidies in financing of HSO and finally refusal of application of subsidies as regular source of financing is planned.

The financial balance of HSO assumes the structured list of the main directions of expenditure of financial resources. The first the block of an account part of balance are the expenses, connected with realization of the main production connected with providing consumers (subscribers) with heat. The expenses of this group include:

- energy import (purchase of energy from a third-party source). The use of this item of expenses has to take place in that case when there is not enough production capacity of the heating system, operating in a certain territory for providing all the subscribers with heat. In this case purchase of heat from the autonomous boiler rooms, operating in this territory and also from the next heating system is possible;

- production of heat - this item of expenditure is the main one in the structure of prime cost for HSO and it includes the expenses, connected with purchase of fuel and its subsequent processing during generation of heat;

- expense of heat for the HSO own needs. The heating system is not only a producer of heat, but also its consumer, as functioning of HSO is impossible without providing the necessary and comfortable thermal mode in buildings and constructions of HSO. The 
expense of heat on the HSO own needs of the organization also has to be considered from an account part of financial balance for ensuring accounting of the full list of expenses of HSO;

- expenses on transportation and distribution of heat include expenses on requirements of technological character for ensuring process of delivery of heat to the consumer, including expenses on the electric power and the water, used within this process;

- the expenses connected with losses during transportation and distribution. Losses of hear are estimated according to power to balance as a difference between the heat, produced and consumed by subscribers. Their existence is caused, first of all, by damages of heating systems and also emergencies. Decrease in such losses is one of the key tasks facing at the moment the Russian HSO. Losses of heat are finally expressed in short-reception of income from its consumption by subscribers (in case of presence of any expenses on its generation). The decrease in expenses of HSO due to the decrease in losses during the transporting and distribution of heat will reduce the cost of services and will allow HSO to offer a competitive tariff (not higher than the level offered by "an alternative boiler room"). In the regions, where it will cause the decrease in a tariff, the appeal of the use of the centralized sources of heat will increase.

The second block of the expenditure part of balance are the expenses, connected with ensuring the heating system maintenance and the heat-generating equipment and also ensuring the decrease in their wear level. These expenses can be carried to expenses of general production character. They include:

- directly maintenance of the heat-generating equipment and systems;

- monitoring of a condition of the heat-generating equipment and systems. The organization of monitoring of a condition of the heating systems allows to estimate not the standard, but actual level of wear, to predict emergencies, to make reasonable plans of routine maintenance and overhaul repairs of systems and also their turns;

- capital repairs of heating systems, their turn, reconstruction and capital repairs and replacement of the heat-generating equipment;

The third block of an expenditure part of balance are indirect expenses and also other expenses:

- overhead costs of HSO are necessary for ensuring its activity and include maintenance costs of structure of business management;

- expenses on the credit (payment of the main part of a debt and percent on the credit). As the sources of financing of HSO assume the use of borrowed funds, (credit financing) as one of the options, it leads to the existence in the expenditure- standard rate of profit. The need of creation of the transparent mechanism of return of the means of the investor which are required at the moment for implementation of large-scale works on updating of pipelines and the heat-generating equipment, leads to allocation of the standard rate of profit as one of the items of expenses. This item is not included into the prime cost, general production or management expenses, however its standard value allows to plan more precisely its size, and the format of financial balance is rather transparent for communication with the investor and demonstration of the directions of the use of its means and the size and regularity of return to the investor (in parts) of the invested capital. part of financial balance of HSO of the corresponding expenses. The application of loan sources of financing for HSO will be justified only if by the results of their use increase in power efficiency in the system of heat supply gives such amount of economy of expenses which will cover the cost connected with service of the credit;

The offered structure of financial balance of HSO clearly demonstrates the sources of financing of its activity with the directions of their use and proves their interconnection. The equality of the balance sections is the necessary condition of normal activity of HSO aimed at providing qualitative and reliable heat supply. 


\section{Discussion}

The offered structure of financial balance will allow to balance the needs for financial resources with sources of their emergence and to replace gradually means of subsidies for alternative sources of financing, including external sources. One of the most perspective for the branch development source is an external source of financing, namely the raised funds (means of the investor).

Certainly, attraction of external sources of financing (proceeds of credit and means of the investor) generate for HSO some obligations, connected with return of means, however their use will allow to carry out the necessary actions for repair, restoration and updating of the heating systems and the equipment, as a result losses of heat will decrease and that will allow to release a part of resources because of the economy, which it will become an inevitable result of the increase in power system effectiveness of the heating system.

Separate explanations need to be given concerning monitoring as the main instrument of collection of information on the heating systems condition. The need of inspection of the condition of pipelines is caused by the fact, that depending on a set of circumstances the level of their wear can differ from the standard level considerably.

The organization of monitoring system is connected with the solution of some questions:

1. choice of a method. During choice of a control method it is necessary to provide the ample opportunities of application, high efficiency and reliability of the results, however such effect is usually reached with the application of several methods in their combination;

2. the organization of accounting of results in the unified information system.

3. the results of inspections need to be considered in a unified information system, which is now provided by the program systems, created on the basis of digital spatial model, allowing to work with information in all the databases relating to heating systems and to present it in the form, convenient for viewing and perception. The passport information on pipelines, and subsequently the information, obtained as a result of inspections is entered into this system. For ensuring the definition of localization of defects, the results are entered into the electronic scheme of the heating systems. Information, accumulated in the system of monitoring allows to make rationally programs of reconstruction and capital repairs for the purpose of extension of a resource of the pipeline to its conclusion in reconstruction [12].

\section{Conclusion}

The HSO balance model, developed and offered as the instrument of management of functioning and development of the heat-supplying organization allows to solve the current problems of the heat supply branch, connected with the lack of financing and unattractiveness for the investor that in turn, does not allow to provide the heat-supplying organizations' activity with the sufficient volume of financial resources for timely repair and updating of heating systems and the heat-generating equipment.

The balance model of functioning and development of HSO is implemented in the mode of financial balance of HSO. It is created on the basis of accounting of sources of financing and the directions of expenditure of financial resources. It allows to create the model of management, aimed at the financial result. The fuel-and-energy balances, used in the current practice, allow to keep account on the basis of units of measure of fuel and they are inefficient for management of financial resources of HSO. That, however, does not reduce their demand for direct management of production, accounting of different types of energy and performance of the purposes of increase in energy efficiency of various branches. Thus, 
it is offered to create the additional instrument of management, based on financial resource management, that is the main type of resources, defining finally existence or lack of other types of resources (material, labour, etc.). Emergence of the new instrument of management is an inevitable consequence of shift of focus of management towards the management financial resources.

\section{References}

1. A. V. Bezhan, V. A. Minin, Thermal Engineering 64 (3), 201-208 (2017)

2. A. F. Sandvall, E. O. Ahlgren, T. Ekvall, Energy Strategy Reviews 18, 212-223 (2017)

3. C. Taylor, The Heat is On for Sustainable District Heating and Cooling (2018) https://www.smartcitiesdive.com/ex/sustainablecitiescollective/heat-planning-districtenergy/1035601/

4. K. Wojdyga, M. Chorzelski, Energy Procedia 116, 106-118 (2017)

5. W. Leontief, The Structure of American Economy (Cambridge, Mass, 1941)

6. International Energy Agency (IEA), World Energy Balance (Paris, IEA, 2010)

7. E. Brabandere, T. Gazzini, Foreign Investment in the Energy Sector: Balancing Private and Public Interests (Martinus Nijhoff Publishers, 2014)

8. D. Quadrelli, Commentary, Understanding and using the Energy Balance (2018) https://www.iea.org/newsroom/news/2017/september/commentary-understanding-andusing-the-energy-balance.html

9. Balance of energy resources for 2015 (data of Federal State Statistics Service) (2017) http://www.gks.ru/free_doc/new_site/business/prom/en_balans.htm

10. N. Verstina, E. Evseev, MATEC Web Conf., 106 (2017)

11. A. Hefnets, Energosovet 7 (12), 16-22 (2010) 